\title{
Effects of physiological environments on the hydration behavior of mineral trioxide aggregate
}

\author{
Yuan-Ling Lee ${ }^{\mathrm{a}}$, Bor-Shiunn Lee ${ }^{\mathrm{a}}$, Feng-Huei Lin ${ }^{\mathrm{b}}$, Ava Yun Lin ${ }^{\mathrm{a}}$, Wan-Hong Lan ${ }^{\mathrm{a}}$, \\ Chun-Pin $\operatorname{Lin}^{\mathrm{a}, *}$ \\ ${ }^{a}$ School of Dentistry, College of Medicine, National Taiwan University \& National Taiwan University Hospital, No. 1, Chang Te Street, \\ Taipei 10016, Taiwan, ROC \\ ${ }^{\mathrm{b}}$ Institute of Biomedical Engineering, National Taiwan University, Taipei 10016, Taiwan, ROC
}

Received 17 February 2003; accepted 14 July 2003

\begin{abstract}
Utilizing scanning electron microscope, X-ray diffraction (XRD) and microhardness tests, we evaluated how various physiological environments affect the hydration behavior and physical properties of mineral trioxide aggregate (MTA). We found that the microstructure of hydrated MTA consists of cubic and needle-like crystals. The former comprised the principal structure of MTA, whereas the later were less prominent and formed in the inter-grain spaces between the cubic crystals. MTA samples were hydrated in distilled water, normal saline, $\mathrm{pH} 7$, and $\mathrm{pH}$ 5. However, no needle-like crystals were observed in the $\mathrm{pH} 5 \mathrm{specimens}$, and erosion of the cubic crystal surfaces was noted. XRD indicated a peak corresponding to Portlandite, a hydration product of MTA, and the peak decreased noticeably in the $\mathrm{pH} 5$ group. The $\mathrm{pH} 5$ specimens' microhardness was also significantly weaker compared to the other three groups $(p<0.0001)$. These findings suggest that physiological environmental effects on MTA formation are determined, in part, by environmental $\mathrm{pH}$ and the presence of ions. In particular, an acidic environment of $\mathrm{pH} 5$ adversely affects both the physical properties and the hydration behavior of MTA.
\end{abstract}

(C) 2003 Elsevier Ltd. All rights reserved.

Keywords: Mineral trioxide aggregate; Acidic pH; SEM; XRD; Microhardness

\section{Introduction}

Apical surgery is performed to remove irritants from the root canal system and to eliminate potential causes of persistent periapical inflammation [1]. Choosing an appropriate retrograde filling material is an important prerequisite to performing successful apical surgery [24]. Root perforation is a frequent complication during endodontic treatment and the preparation of post space, causing, among other periodontal defects, an inflammatory reaction in the contact tissue. To solve these root perforation induced problems, a suitable material is the key to successfully sealing the artificial channel [5-8]. An ideal material for retrograde filling or perforation repair should adhere to the root canal wall while maintaining sufficient sealing and be easy to handle as well as

*Corresponding author. Tel.: + 886-2-23123456x7335; fax: + 886-223821212.

E-mail address: pinlin@ha.mc.ntu.edu.tw (C.-P. Lin). biocompatible or bioactive. In addition, the material should be dimensionally stable, insoluble in tissue fluids, non-resobable, and radiopaque [3,7,9]. While a number of substances such as amalgam, Super EBA, IRM, composite resin, and glass ionomer have been commonly used as retrograde filling or perforation repair materials, none of these materials have been able to satisfy the requirements of an ideal material $[3,4,8]$.

Mineral trioxide aggregate (MTA), developed in 1993, is a potential alternative to traditional materials. MTA is designed to seal the pathways of communication between the root canal system and the periodontium and has been recommended as a material for use in perforation repair and retrograde filling [10]. Several in vitro and in vivo studies have demonstrated that the sealing ability and biocompatibility of MTA are superior to that of amalgam, IRM and Super EBA [10-13]. Animal studies of both furcal perforation repair and retrograde filling with MTA revealed the formation of a continuous layer of new cementum over the excess 
material $[14,15]$. Hence, MTA has been regarded as a material with bioactive potential. In addition, MTA possesses high $\mathrm{pH}$ and radiopacity values [16]. However, it is not easy to handle, and obtaining consistent results in clinical applications can be difficult. The particle sizes, powder to liquid ratio, environmental temperature, and presence of air in the mixture may all affect the physical properties of MTA $[10,16]$. In addition, a possible disadvantage of MTA is its long setting time, because many environmental factors may affect the properties of MTA during setting. Hence, some researchers have offered differing opinions on whether MTA is really superior to other materials in terms of sealing [17]. Therefore, before we judge whether MTA is an ideal material for retrograde filling or perforation repair, more studies which focus on the setting mechanism and microstructure of MTA are requisite to fully explaining the behavior of MTA in clinical applications.

Torabinejad and Chivian suggested that MTA might remain soft when placed in perforations with a high degree of inflammation, and the inflamed area surrounding the involved tooth may have an acidic $\mathrm{pH}$ as low as 5.5-5.6 [18,19]. A study of the tricalcium silicate complex, the principal composition of MTA, demonstrated that the silicate in the complex could be dissolved in $20 \%$ salicylic acid or $20 \%$ maleic acid [20]. Furthermore, Nilforoushan and Sharp reported that the lithium salts of the environment, including sodium chloride, have a particularly notable effect on the chemical reactions of calcium complex cement [21]. From these investigations, it can be assumed that environmental factors, such as acidic $\mathrm{pH}$ or the types of surrounding ions, could affect the setting reactions of MTA. However, only a handful of studies have focused on this topic, and as a result, the effects on MTA properties of both environmental acidity and the presence of ions remain unclear.

Therefore, the purpose of this study was to investigate via scanning electron microscopy, X-ray diffraction analysis and microhardness testing, the microstructure and hydration behavior of MTA in various physiological environments.

\section{Materials and methods}

\subsection{Preparation of specimens}

A commercially available MTA (ProRoot, Dentsply/ Tulsa Dental, Tulsa, OK) was mixed with sterile water at a powder to liquid ratio of 3:1 in accordance with the manufacturer's instructions. Subsequently, the mixture was incrementally placed into the mold with a spatula and condensed with a condenser. After 2 min of mixing, the specimens were randomly divided into four groups and stored at $37^{\circ} \mathrm{C}$ in distilled water (group 1), normal saline (group 2), $\mathrm{pH} 7$ (group 3) and $\mathrm{pH} 5$ (group 4) solutions, respectively. Seven days later, all specimens were removed from the experimental solutions and airdried overnight at room temperature.

\subsection{SEM observation}

The specimen surfaces of the various groups were examined with a scanning electron microscope (SEM, Topcon ABT-60, Japan). Five specimens were prepared from each of the four groups for morphological observation by SEM. After air drying overnight at room temperature, the specimens were mounted on aluminum stubs and sputter-coated with gold by Sputter Coater (BIO-RED SC 502, Fisons plc Registered Office, England). Finally, the surface characteristics of the specimens were examined under by SEM and recorded with the analySiS ${ }^{\circledR} 3.0$ digital imaging system (Soft Imaging System GmbH, Germany). The original MTA powders were also prepared for SEM observation via the same procedure to exam the MTA before hydration.

\subsection{XRD analysis}

The crystalline phases of MTA before and after hydration were determined by X-ray diffraction (XRD) analysis. The specimens were milled into powder by mortar and pestle, and the XRD patterns were recorded with the Rigaku X-ray powder diffractometer (Rigaku, Geigerflex, Japan) with $\mathrm{Ni}$ filter and $\mathrm{CuK}_{\alpha}$ radiation $(\lambda=0.154 \mathrm{~nm})$, which was generated at $30 \mathrm{kV}$ and $20 \mathrm{~mA}$. The samples were scanned at a range from $10^{\circ}$ to $60^{\circ}$, and all data were collected in a continuous scan mode at a scanning rate of $4^{\circ} / \mathrm{min}$. Crystalline formations were identified by a computer auto-matched system with a standard data file of JCPDS. The original MTA powders were also analyzed by XRD to compare hydrated and unhydrated MTA.

\subsection{Microhardness test}

Ten specimens from each of the four groups were prepared for microhardness testing using a microhardness tester (SHIMADZU HMV-2, Japan). Before testing, the specimen surfaces were wet-ground with 1000-grit silicon carbide paper at room temperature. The Knoop hardness test was performed using a diamond indenter with $98.07 \mathrm{mN}$ load and $6 \mathrm{~s}$ dwell time. Five measurements were made on the surface of each of the specimens, and the average value was taken as the hardness of that particular specimen. The microhardness values recorded for each group were tested for statistical significance by one-way analysis of variance (ANOVA). Statistical significance was assumed in advance to be at a probability level of 0.05 . When differences were found, Tukey's multiple comparison 

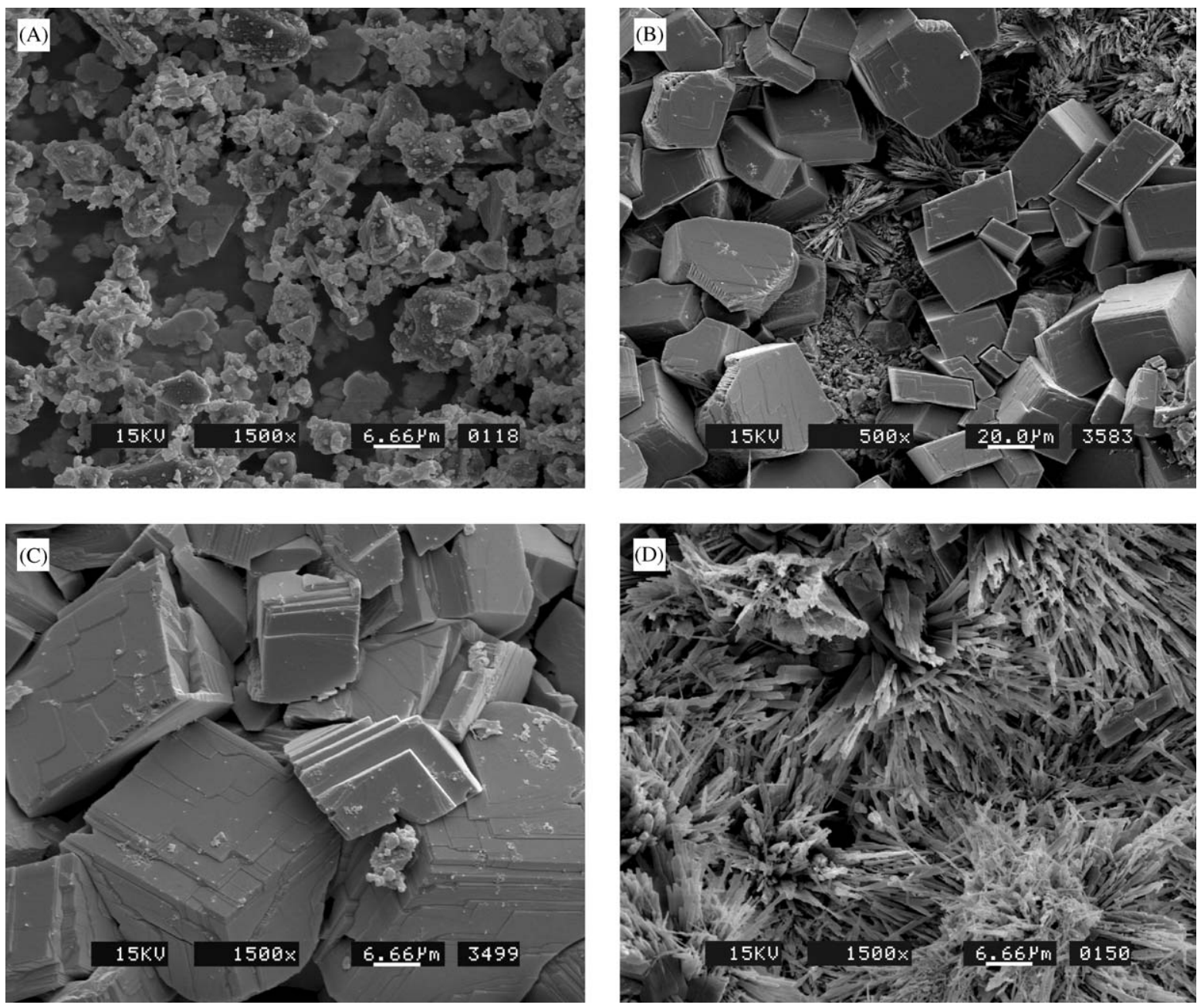

Fig. 1. (A) SEM micrograph of MTA before hydration. (B, C, D) MTA after hydration in distilled water. The crystalline formation appears irregular in shape and size, and the surfaces of the cubic crystals appear uneven, while the needle-like crystals have developed in a jagged manner.

test was used to isolate the statistically significant subgroup at the $95 \%$ confidence level.

\section{Results}

\subsection{SEM}

Before hydration, the MTA powder particles, illustrated in Fig. 1(A), ranged in size from 1 to $10 \mu \mathrm{m}$. Morphological observations revealed that the hydrated MTA stored in distilled water possessed a microstructure resembling an epitaxially growth pattern, which consists of cubic and needle-like crystals, shown in Fig. 1(B). The cubic crystals dominated the hydrated MTA structure, whereas the needle-like crystals were less significant and formed in the inter-grain spaces between the cubic crystals. Fig. 1(C) shows a closer examination of the cubic crystals in the distilled water sample and further reveals the presence of lightly stratified structures on the surface of the cubic crystals. All cubic crystals interlocked with each other at a constant angle and direction to form the basic framework of the hydrated MTA. The needle-like crystals, meanwhile, appeared to form in thick bundles with sharp extremities, shown in Fig. 1(D). In general, the crystallized structure which formed after treatment with distilled water appeared irregular in both shape and size. Specifically, the surfaces of the cubic crystals appeared uneven, while the needle-like crystals developed in a jagged manner.

The microstructures of the specimens stored in both the normal saline and $\mathrm{pH} 7$ environments also exhibited epitaxilly growth patterns. The cubic crystals contributed to the framework of the resulting structures, and the needle-like crystals filled in the inter-grain space. The size of the crystallized formation appeared larger, however, and the overall structure seemed less intricate than the crystalline configuration from the distilled water specimens. Also, compared to the distilled water specimens, additional laminated formations were present on the outer portion of the cubic crystals in the 

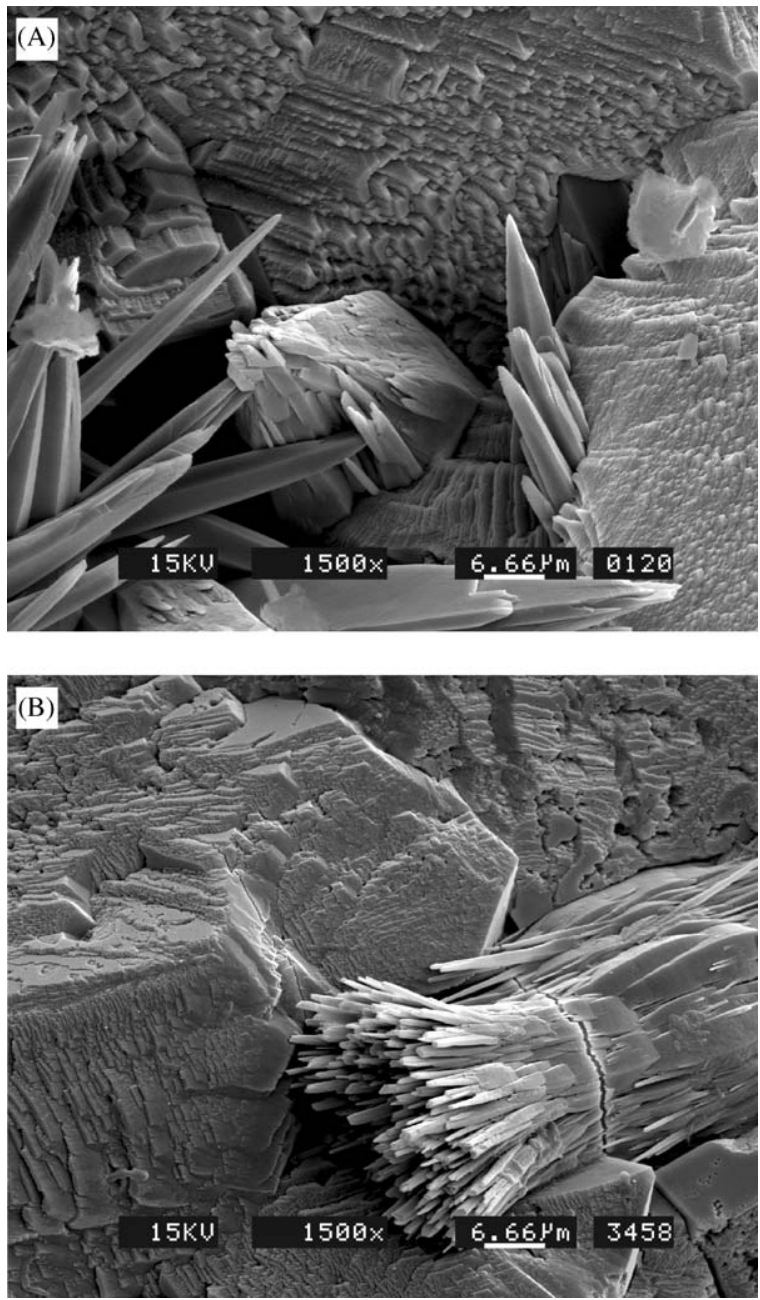

Fig. 2. (A) SEM micrograph of MTA stored in normal saline. (B) MTA stored in $\mathrm{pH}$ 7. Though the crystalline structures are fairly well developed their shapes and sizes are not as irregular as the distilled water induced formation.

normal saline and $\mathrm{pH} 7$ groups, shown in Fig. 2. Moreover, the lightly stratified structures present on the distilled water induced cubic crystals were not demonstrated in these specimens.

In the $\mathrm{pH} 5$ specimens, the microstructure of MTA consisted of relatively undeveloped cubic crystals. Furthermore, the SEM results of hydrated MTA stored in $\mathrm{pH} 5$ revealed that no needle-like crystals were found throughout the materials, shown in Fig. 3(A). The crystal boundaries were less distinct and the grains less defined than those observed in the distilled water specimens. Fig. 3(B) shows that erosive surfaces were also observed over the cubic crystals, and a differential etching pattern was noted in these specimens.

\section{2. $X R D$}

Fig. 4 displays the XRD powder patterns of unhydrated and hydrated MTA stored in distilled
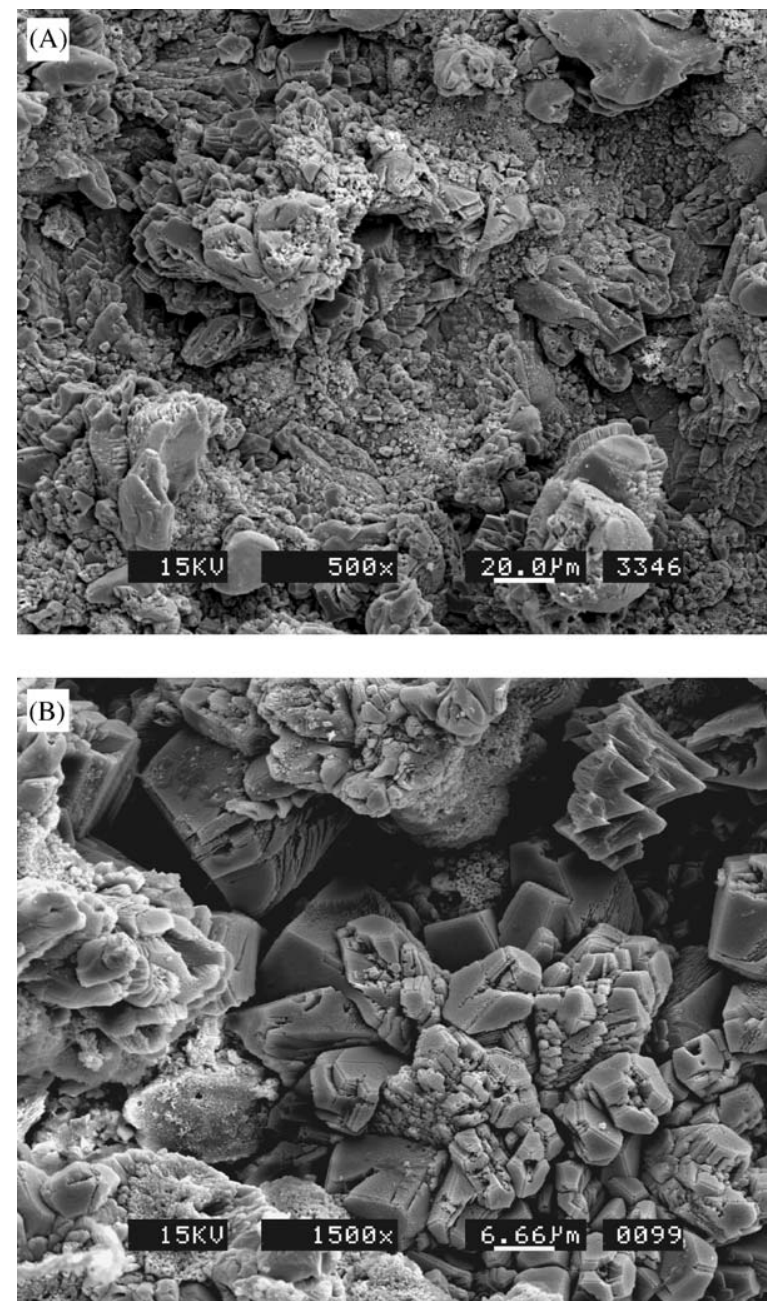

Fig. 3. (A,B) SEM micrographs of MTA stored in pH 5. Clearly, the crystalline structure maturity pales in contrast to the formations of the other specimens.

water, normal saline, $\mathrm{pH} 7$ and $\mathrm{pH}$ 5. For the sample of unhydrated MTA, several sharp peaks of $\mathrm{C}_{3} \mathrm{~S}\left(3 \mathrm{CaO} \cdot \mathrm{SiO}_{2}\right), \mathrm{C}_{2} \mathrm{~S}\left(2 \mathrm{CaO} \cdot \mathrm{SiO}_{2}\right)$, and $\mathrm{C}_{3} \mathrm{~A}$ $\left(3 \mathrm{CaO} \cdot \mathrm{Al}_{2} \mathrm{O}_{3}\right)$ were recorded. Both a large peak at $2 \theta=27.3^{\circ}$ and a slight broadening of the multiple peaks at $2 \theta=32^{\circ}-34^{\circ}$ were observed. A similar XRD powder pattern was observed among the hydrated MTA groups, which included the distilled water, normal saline, $\mathrm{pH} 7$ and $\mathrm{pH} 5$ groups. Three phases of $\mathrm{C}_{3} \mathrm{~S}, \mathrm{C}_{2} \mathrm{~S}$ and $\mathrm{C}_{3} \mathrm{~A}$ were identified at the same location. However, the line intensities for the peaks of these three phases decreased after hydration. For the hydrated MTA specimens, the peak intensities of these three phases were nearly identical to the peaks for the groups of distilled water, normal saline, and $\mathrm{pH}$ 7. There was only a slight high in the group of $\mathrm{pH}$ 5. An additional sharp peak at $2 \theta=18^{\circ}$ for hydrated MTA was noted, and the intensities were similar except for the $\mathrm{pH} 5$ group, where an obvious decrease in intensity for the additional peak was observed. 


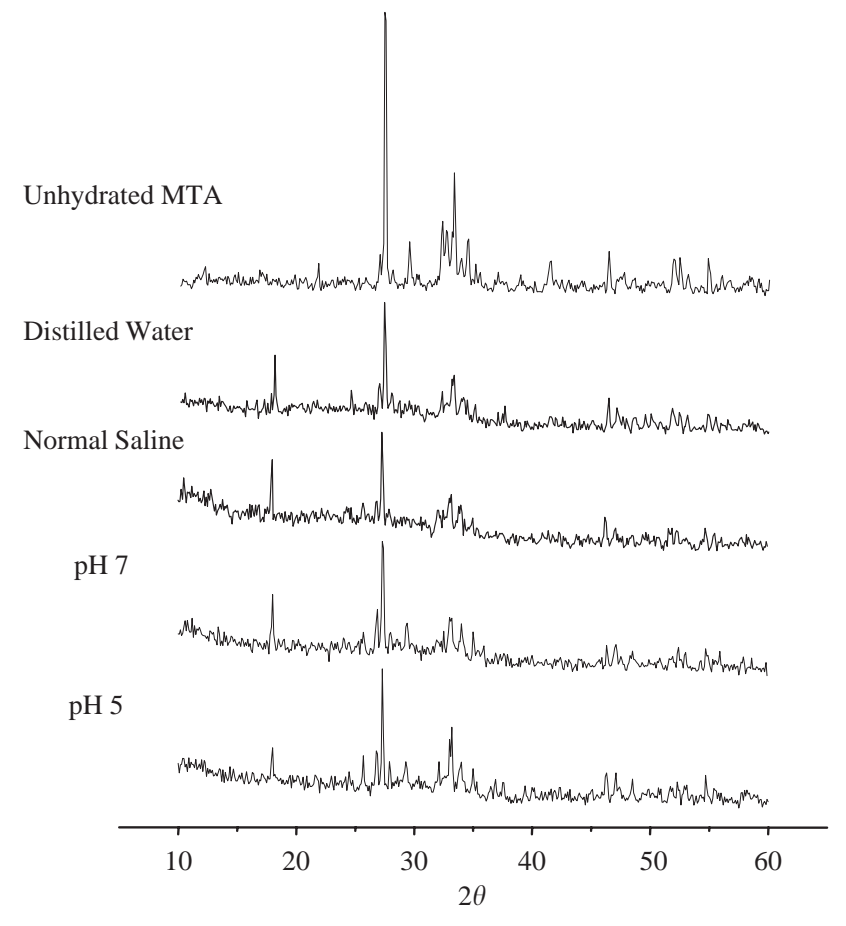

Fig. 4. XRD powder patterns of unhydrated MTA and hydrated MTA stored in distilled water, normal saline, $\mathrm{pH} \mathrm{7,} \mathrm{and} \mathrm{pH} 5$. Portlandite and reactant peaks are observable in each pattern, and both peaks are lower in the $\mathrm{pH} 5$ pattern.

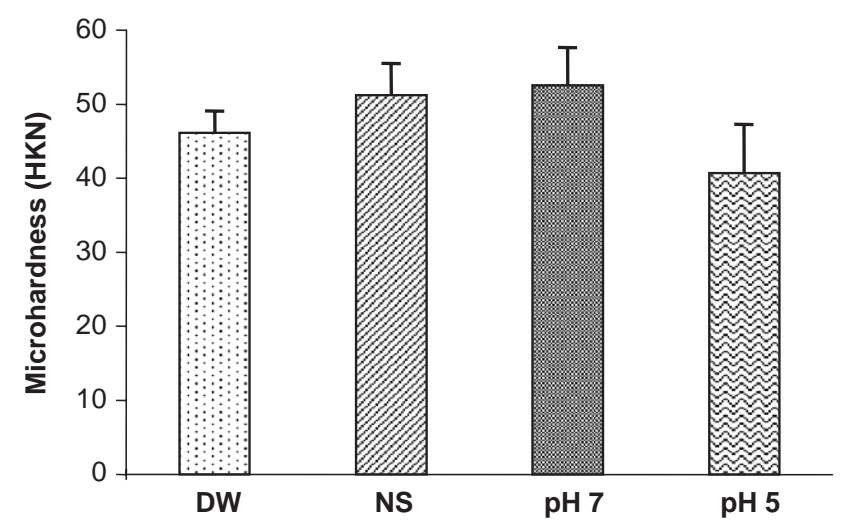

Fig. 5. Microhardness test results for each group. The pH 5 group ranked the lowest, while the $\mathrm{pH} 7$ group ranked the highest.

\subsection{Microhardness}

The results of the microhardness test are shown in Fig. 5. The means and standard deviations of microhardness for distilled water, normal saline, $\mathrm{pH} 7$ and $\mathrm{pH}$ 5 were $46.619 \pm 3.878,51.206 \pm 4.094,52.25 \pm 4.375$ and $40.738 \pm 6.501 \mathrm{HKN}$, respectively. A one-way ANOVA test showed a significant difference among the four groups $(p<0.0001)$. The mean microhardness of the pH 5 specimens was significantly lower than the other three samples $(p<0.0001)$. The mean microhardness of the $\mathrm{pH} 7$ samples was significantly greater than the distilled water specimens $(p<0.0183)$. The mean microhardness of the normal saline samples was not significantly different from the distilled water $(p=$ $0.0544)$ and $\mathrm{pH} 7(p=0.6322)$ samples. The $\mathrm{pH} 5$ specimens' microhardness was the weakest of all the samples.

\section{Discussion}

MTA is a type of mineral cement which solidifies as a hard structure upon hydration [10], a process that occurs with the dissolution of the anhydrous phases of MTA followed by the crystallization of the hydrates in an interlocking mass [20]. This crystallization consists of the formation of cubic and needle-like crystals and can be explained in terms of crystal kinetics. Due to the complexity of MTA components, which include particles of tricalcium silicate $\left(\mathrm{C}_{3} \mathrm{~S}\right)$, tricalcium aluminate $\left(\mathrm{C}_{3} \mathrm{~A}\right)$, tricalcium oxide, silicate oxide, mineral oxide, and bismuth oxide [22], their nucleation rates may differ [23], and some parts may form hydration products more rapidly than others.

Estrela et al. reported that MTA and Portland cement contain the same chemical elements with the exception of bismuth oxide, which is added to MTA to increase radiopacity [24]. Thus, MTA hydration should resemble that of Portland cement, which produces calcium silicate hydrates (C-S-H) and Portlandite [20,25-29]. XRD analysis indicated a decrease in the characteristic peak intensities of $\mathrm{C}_{3} \mathrm{~S}, \mathrm{C}_{2} \mathrm{~S}$, and $\mathrm{C}_{3} \mathrm{~A}$ after MTA hydration. Because these reactants dissolved in water to form hydrated products, a reduction in quantities of $\mathrm{C}_{3} \mathrm{~S}$, $\mathrm{C}_{2} \mathrm{~S}$, and $\mathrm{C}_{3} \mathrm{~A}$ after MTA hydration was expected. Furthermore, Fig. 4 illustrates that the sharp peak at $18^{\circ}$ corresponding to Portlandite in hydrated MTA was also observed, suggesting that the final $\mathrm{C} / \mathrm{S}$ ratio of MTA should be greater than 1.5, which correlates with Cong and Kirkpatrick's report [26] that the type of developing $\mathrm{C}-\mathrm{S}-\mathrm{H}$ phases is influenced by the $\mathrm{C} / \mathrm{S}$ ratio. However, the exact composition of the $\mathrm{C}-\mathrm{S}-\mathrm{H}$ phases at different $\mathrm{C} / \mathrm{S}$ ratios remains unclear. Laminated constructions on the surface of the cubic crystals were also noted, and considering the layered structure of $\mathrm{C}-\mathrm{S}-\mathrm{H}$ phases [27], shown in Figs. 1(C), 2(A) and (B), it is possible that these stratified or laminated constructions are related to $\mathrm{C}-\mathrm{S}-\mathrm{H}$ formation. Due to the small crystal size of C-S-H [29,30], however, only Portlandite was identifiable in hydrated MTA. Considering Portlandite is essentially crystalline calcium hydroxide, the reaction mechanism in MTA is probably similar to that of calcium hydroxide. In fact, several studies with animals discovered that MTA and calcium hydroxide behave similarly when inducing the formation of dentinal bridges or the proliferation of osteoblast $[31,32]$. 
Pulpal and periapical inflammation typically lowers the tissue $\mathrm{pH}$ near the involved tooth to around 5.5 [19]. As a result, MTA may come in contact with inflammatory tissue when used for perforation repair or retrograde filling. Roy et al. set experimental factors at $\mathrm{pH}$ 5.0 and $\mathrm{pH} 7.4$ to evaluate how an acidic environment affects the leakage of root-end filling materials [33]. In this study, only cubic crystals were found in the MTA hydrated in acidic pH, shown in Fig. 3(A). The absence of needle-like crystals may be because the large surface areas of such crystals provide numerous reaction sites for fast dissolution in an acidic environment. According to Bye, hydrated Portland cement can be dissolved in $20 \%$ salicylic acid or $20 \%$ maleic acid [20]. Composition similarities between Portland cement and MTA imply that MTA crystals may also dissolve in an acidic condition. Based on these findings, the crystalline structure of the $\mathrm{pH} 5$ group appears to be the least cohesive.

A decrease in the characteristic peak intensities of the MTA reactants was observed in this study, but the additional sharp peak corresponding to Portlandite, illustrated in Fig. 4, was also identified in the $\mathrm{pH} 5$ specimens after hydration, suggesting that MTA can still be hydrated in $\mathrm{pH} 5$ environments and that $\mathrm{C}_{3} \mathrm{~S}, \mathrm{C}_{2} \mathrm{~S}$, and $\mathrm{C}_{3} \mathrm{~A}$ will dissolve in an acidic environment before precipitating to form Portlandite. SEM results displayed the same phenomenon, shown in Figs. 1(A) and 3(A). Lower peak intensities of Portlandite and the reactants in $\mathrm{pH} 5$ specimens compared to the normal samples suggest that a decrease in environmental $\mathrm{pH}$ retards the dissolution of reactants such as $\mathrm{C}_{3} \mathrm{~S}, \mathrm{C}_{2} \mathrm{~S}$ and $\mathrm{C}_{3} \mathrm{~A}$, thus decreasing the production of Portlandite crystals. Essentially, the $\mathrm{pH} 5$ environment inhibited the reaction to hydration of MTA. It is possible, however, that the hydrated product was dissolved in the acidic environment after formation, which would also account for the decrease in peak intensity of Portlandite.

SEM and XRD results both suggested that lowering the environmental $\mathrm{pH}$ can be detrimental to MTA microstructure. The $\mathrm{pH} 5$ specimens exhibited a significantly lower hardness value than the other samples in the microhardness test, shown in Fig. 5, and an analysis of the MTA microstructure revealed that both the crystal surfaces were dissolved, which signifies structural weakening. The needle-like crystals are important in interlocking the entire mass of material, and their disappearance caused the material hardness to decrease. In instances of incomplete reaction, the strength, hardness, and other relevant physical properties of MTA were also adversely affected. Based on this study and the clinical experiences of other researchers $[18,22]$, using MTA as a filling material in a highly inflamed area appears detrimental to the material's microstructure and other physical properties. Thus, before applying MTA on an inflamed area, treating the inflammation with an alkaline medication such as $\mathrm{Ca}(\mathrm{OH})_{2}$ may be advisable to neutralize the environmental $\mathrm{pH}$ and allow the material to perform optimally.

MTA has been regarded as an ideal material for perforation repair, retrograde filling, pulp capping, and apexification since its introduction in 1993. Various studies have demonstrated its excellent sealing ability and biocompatibility [10-12,14]. However, a disadvantage of MTA is its long setting time, because stabilizing it long enough to allow setting can be difficult [17]. This study supports the hypothesis that an acidic environment affects the setting of MTA by interfering with the crystallization of the cubic and needle-like crystals. More specifically, this investigation has shown that a $\mathrm{pH}$ 5 environment does indeed affect MTA hydration. To understand the pathways and mechanisms of MTA formation in greater detail, future studies could focus on how different $\mathrm{pH}$ values affect the material properties of MTA.

\section{Conclusion}

This study utilized SEM, XRD and microhardness tests to investigate the microstructure and hydration behavior of MTA in various physiological environments. Specimens hydrated in distilled water, normal saline, and $\mathrm{pH} 7$ indicated that the microstructure of hydrated MTA consists of cubic and needle-like crystals. While the cubic crystals formed the principal structure of MTA, the needle-like crystals formed between the cubic crystals and were less prominent. In addition, XRD indicated a peak corresponding to Portlandite, a hydration product of MTA. In the $\mathrm{pH} 5$ hydrated specimens, however, not only were needle-like crystals observed, but erosion of the cubic crystal surfaces was noted as well. Moreover, the Portlandite peak decreased noticeably in the $\mathrm{pH} 5$ group, and the microhardness of the $\mathrm{pH} 5$ specimens was also significantly weaker compared to the other three specimen groups $(p<0.0001)$. Essentially, the results revealed that an acidic environment such as $\mathrm{pH} 5$ is detrimental to the physical properties and hydration behavior of MTA. This finding suggests that the physiological environmental effects on MTA formation are determined, at least in part, by environmental $\mathrm{pH}$.

\section{References}

[1] McDonald NJ, Hovland EJ. Surgical endodontics. In: Walton RE, Torabinejad M, editors. Principles and practice of endodontics, 2nd ed. Philadelphia: W.B. Saunders Co.; 1996, p. 401-22.

[2] Firedman S. Retrograde approaches in endodontic therapy. Endod Dent Traumatol 1991;7:97-107. 
[3] Johnson BR. Considerations in the selection of a root-end filling material. Oral Surg Oral Med Oral Pathol Oral Radiol Endod 1999;87:398-404.

[4] Jou YT, Pertl C. Is there a best retrograde filling material? Dent Clin North Am 1997;41:555-61.

[5] Ingle JI, Simon JH, Machtou P, Bogaerts P. Outcome of endodontic treatment and re-treatment. In: Ingle JI, Backland LK, editors. Endodontics, 5th ed. Hamilton, London: BC Decker Inc.; 2002. p. 753-5.

[6] Lemon RR. Nonsurgical repair of perforation defects. Dent Clin North Am 1992;36:439-57.

[7] Alhadainy HA. Root perforations. Oral Surg Oral Med Oral Pathol 1994;78:368-74.

[8] Bryan EB, Wollard G, Mitchell WC. Nonsurgical repair of furcal perforations: a literature review. Gen Dent 1999;47: 274-80.

[9] Kim S. Endodontic microsurgery. In: Cohen S, Burns RC, editors. Pathways of the pulp. 8th ed. St. Louis: Mosby; 2002. p. $718-21$.

[10] Lee SJ, Monsef M, Torabinejad M. Sealing ability of a mineral trioxide aggregate for repair of lateral root perforations. J Endodontics 1993;19:541-4.

[11] Torabinejad M, Watson TF, Pitt Ford TR. Sealing ability of a mineral trioxide aggregate when used as a root end filling material. J Endodontics 1993;19:591-5.

[12] Osorio RM, Hefti A, Vertucci FJ, Shawley AL. Cytotoxicity of endodontic materials. J Endodontics 1998;24:91-6.

[13] Koh ET, McDonald F, Pitt Ford TR, Torabinejad M. Cellular response to mineral trioxide aggregate. J Endodontics 1998;24:543-7.

[14] Pitt Ford TR, Torabinejad M, McKendry DJ, Hong CU, Kariyawasam SP. Use of mineral trioxide aggregate for repair of furcal perforations. Oral Surg Oral Med Oral Pathol Oral Radiol Endod 1995;79:756-63.

[15] Torabinejad M, Hong CU, Lee SJ, Monsef M, Pitt Ford TR. Investigation of mineral trioxide aggregate for root-end filling in dogs. J Endodontics 1995;21:603-8.

[16] Torabinejad M, Hong CU, McDonald MF, Pitt Ford TR. Physical and chemical properties of new root-end filling material. J Endodontics 1995;25:349-53.

[17] Weldon J, Pashley DH, Loushine RJ, Weller RN, Kimbrough WF. Sealing ability of mineral trioxide aggregate and Super-EBA when used as furcation repair materials: a longitudinal study. J Endodontics 2002;28:467-70.

[18] Torabinejad M, Chivian N. Clinical applications of mineral trioxide aggregate. J Endodontics 1999;25:197-205.
[19] Malamed SF. In: Local anesthetic considerations in dental specialties: handbook of local anesthesia, 4th ed. St. Louis: Mosby-Year Book; 1997. p. 232 [Chapter 16].

[20] Bye GC. Portland cement: composition, production and properties. Oxford: Pergamon Press; 1983.

[21] Niforoushan MR, Sharp JH. The effect of additions of alkalineearth metal chlorides on the setting behavior of a refractory calcium aluminate cement. Cem Concr Res 1995;25:1523-34.

[22] Schmitt D, Lee J, Bogen G. Multifacted use of ProRoot ${ }^{\mathrm{TM}}$ MTA root canal repair material. Am Acad Pediatric Dent 2001;23: 326-30.

[23] Bentur A. Cementitious materials-nine millennia and a new century: past, present, and future. J Mater Civil Eng 2002;14:2-22.

[24] Estrela C, Bammann LL, Estrela CRA, Sliva RS, Pécora JD. Antimicrobial and chemical study of MTA, Portland cement, calcium hydroxide paste, Sealapex and Dycal. Braz Dent J 2000;11:3-9.

[25] Masse S, Zanni H, Lecourtier J, Roussel JC, Rivereau A. High temperature hydration of tricalcium silicate, the major component of Portland cement: a silicon-29 NMR contribution. J Chim Phys 1995;92:1861-6.

[26] Cong X, Kirkpatrick RJ. ${ }^{29} \mathrm{Si}$ MAS study of the structure of calcium silicate hydrate. Adv Cem Based Mater 1996;3:144-56.

[27] Gauffinet S, Finot É, Lesniewska E, Nonat A. Direct observation of the growth of calcium silicate hydrate on alite and silica surface by atomic force microscopy. Earth Planet Sci 1998;327:231-6.

[28] Brown PW. Hydration behavior of calcium phosphates is analogous to hydration behavior of calcium silicates. Cem Concr Res 1999;29:1167-71.

[29] Consolati G, Dotelli, Quasso F. Investigation of nanostructures in ordinary Portland cement through positron annihilation spectroscopy. J Appl Phys 1999;86:4225-31.

[30] Häußler F, Palzer S, Eckart A. Nondestructive microstructural investigations on hydrating cement paste and tricalcium silicate by small angle neutron scattering. Leipz Annu Civil Eng Rep 1999;4:47-64.

[31] Pitt Ford TR, Torabinejad M, Abedi HR, Bakland LK, Kariyawasam SP. Using mineral trioxide aggregate as a pulpcapping material. J Am Dental Assoc 1996;127:1491-4.

[32] Holland R, de Souza V, Nery MJ, Otoboni Filho JA, Bernabe PF, Dezan Junior E. Reaction of rat connective tissue to implanted dentin tubes filled with mineral trioxide aggregate or calcium hydroxide. J Endodontics 1999;25:161-6.

[33] Roy CO, Jeansonne BG, Gerrets TF. Effect of an acid environment on leakage of root-end filling materials. J Endodontics $2001 ; 27: 7-8$. 